\title{
PCR assay confirms diagnosis in syndrome with variably expressed phenotype: mutation detection in Stickler syndrome
}

\author{
N N Ahmad, D M McDonald-McGinn, P Dixon, E H Zackai, W S Tasman
}

\begin{abstract}
Stickler syndrome is an autosomal dominant disease with ocular (severe myopia, vitreal degeneration, and retinal detachment) and other systemic manifestations (hearing loss, cleft palate, epiphyseal dysplasia, and premature osteoarthritis). As with other dominantly inherited conditions, the clinical phenotype of Stickler syndrome varies considerably. To date, all mutations have been located in the type II procollagen (COL2A1) gene. Analysis of a $C \rightarrow T$ mutation we had identified previously, in COL2A1 gene in exon 40, in a three generation pedigree showed the loss of a cleavage site for the $\operatorname{TaqI}$ restriction enzyme. We designed a rapid PCR based restriction enzyme assay to detect this mutation and used it to establish the diagnosis in a neonate from the same pedigree, presenting with the first occurrence of the Pierre-Robin sequence in the family and minimal ocular findings. These results underline the potential diagnostic value of many as yet undetected DNA mutations in families affected with Stickler syndrome, since the variability of the phenotype can impede accurate diagnosis, appropriate genetic counselling, and effective intervention and prophylactic treatment for affected people. $(\mathcal{F}$ Med Genet 1996;33:678-681)
\end{abstract}

Key words: Stickler syndrome; COL2A1 gene.

Stickler syndrome (arthro-ophthalmopathy) is characterised by autosomal dominant inheritance and variable manifestations of myopia, vitreoretinal degeneration, and retinal detachment, associated with osteoarthritis, cleft palate, and other systemic findings. ${ }^{1-3}$ As with other dominantly inherited conditions, the clinical manifestations of Stickler syndrome vary considerably, which is an area of potential concern regarding accurate diagnosis, appropriate genetic counselling, and effective intervention and prophylactic treatment for affected people. A precise diagnosis before counselling is ideal, but accurate ophthalmic diagnosis is not sufficient to clarify the inheritance owing to the intrafamilial variability of the phenotype. To date, all mutations in families affected with Stickler syndrome have been located in the gene for type II procollagen (COL2A1)..$^{4-9}$ However, linkage studies have indicated locus heterogeneity, ${ }^{10-12}$ with about two-thirds of the families showing linkage to the COL2Al gene. There have also been reports of other disorders sharing clinical features of Stickler syndrome but which either had none of the ocular findings and were linked to the COL11A2 gene locus ${ }^{13}{ }^{14}$ or had a subset of only the ocular findings with no other systemic findings, such as Wagner disease and erosive vitreoretinopathy, with linkage to chromosome $5 \mathrm{q} 13-14 .{ }^{15}$

Diagnostic tests for such a predisposition to Stickler syndrome based on identification of the mutation in the COL2A1 gene allows genetic counselling and effective intervention and prophylactic treatment for affected people. We report the loss of a cleavage site for the TaqI restriction enzyme created by a $\mathrm{C} \rightarrow \mathrm{T}$ mutation in the COL2A1 gene converting arginine codon (CGA) to a premature stop codon (TGA), which we had previously identified in a three generation pedigree. ${ }^{4}$ We describe a polymerase chain reaction (PCR) based restriction enzyme assay of the TaqI mutation in exon 40 of the COL2A1 gene, which is a rapid screening diagnostic method to identify the mutant allele in this pedigree. This assay was used to establish the diagnosis in a neonate from the same pedigree, presenting with the Pierre-Robin sequence, with some minimal ocular findings.

\section{Methods}

A neonate born to a member (II.2) of a three generation pedigree (fig 1) affected with Stickler syndrome, whom we had studied previously, ${ }^{4}$ presented with the Pierre Robin sequence (glossoptosis, cleft palate, micrognathia). At birth he presented with subcostal retractions and stridor and required endotracheal intubation. He exhibited midfacial hypoplasia and ophthalmological examination showed - 0.5 diopters OD, plano OS. The obstruction did not resolve within several weeks and a tracheotomy was performed.

Genomic DNA was isolated from peripheral blood leucocytes of the neonate (III.2) and the original proband (II.1) and his son (III.1) from whom fresh samples were obtained for this study. II. 2 was not available for either the previous or present study.

DNA AMPLIFICATION, RESTRICTION DIGEST, AND SEQUENCE ANALYSIS

A 631 bp product containing exon 40 and its flanking intronic regions and exon 41 was amplified by PCR using the genomic DNA as template. The oligonucleotide primers for this $631 \mathrm{bp}$ product were 
5'-GAAACTGCTGTCACTGAG-3' (forward primer) and 5'-CAAGGCTTCTACCTCCCTCA-3' (reverse primer).

The PCR amplification was carried out in a $100 \mu \mathrm{l}$ reaction volume with $T a q$ polymerase and 20 pmol of each primer. The DNA was amplified for 35 cycles using a Perkin Elmer Cetus 9600 Thermocycler: denaturation, $94^{\circ} \mathrm{C}, 30$ seconds; annealing, $54^{\circ} \mathrm{C}, 30$ seconds; extension, $72^{\circ} \mathrm{C}$, one minute 10 seconds with a one second addition to the extension step for each cycle of the amplification. The thermocycling was preceded by a 10 second incubation at $94^{\circ} \mathrm{C}$ and followed by a two minute incubation at $72^{\circ} \mathrm{C}$. The PCR product was completely dried down and the final pellet was resuspended in $10 \mu \mathrm{l}$ of distilled water. The DNA was digested by TaqI (Gibco BRL) at

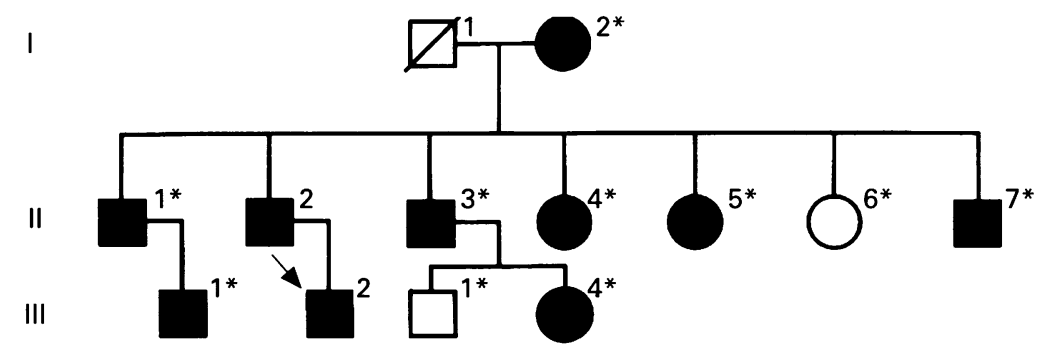

4 Case reported here

* Case reported previously

Figure 1 Pedigree of family affected with Stickler syndrome. The filled symbols indicate affected subjects.
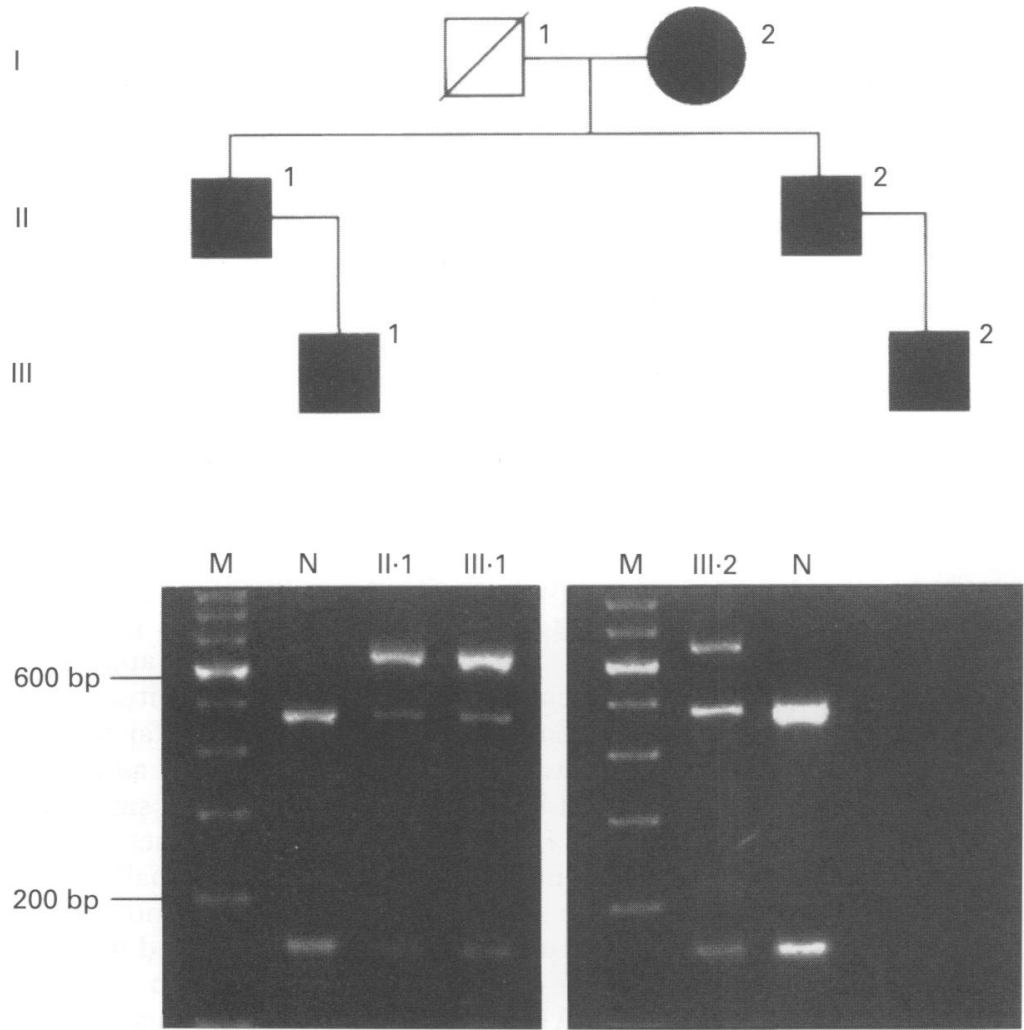

Figure 2 Partial family pedigree and TaqI restriction endonuclease digestion of PCR amplified DNA. PCR products from the normal homozygote is cleaved into two fragments of of $475 \mathrm{bp}$ and $156 \mathrm{bp}$. The mutation destroyed this unique TaqI site and the presence of the $631 \mathrm{bp}, 475 \mathrm{bp}$, and $156 \mathrm{bp}$ fragments is characteristic of the affected heterozygote. $M=$ $100 \mathrm{bp} D N A$ ladder, $N=$ normal subject, $b p=$ base pair. $65^{\circ} \mathrm{C}$ for three hours. The resulting products were analyed by electrophoresis in a $2.5 \%$ agarose gel.

DNA SEQUENCING

The restriction analysis results were verified by direct sequencing. The DNA was amplified asymmetrically using the same cycling parameters, except that the annealing temperature was $56^{\circ} \mathrm{C}$ and the total number of cycles was 25. The first amplification was performed with a concentration of $5 \mathrm{pmol}$ of the limiting primer and $20 \mathrm{pmol}$ of the excess primer. The second, highly asymmetrical amplification was performed using $1 \mu \mathrm{l}$ of the first amplification product as template in $100 \mathrm{ml}$ reaction mixture, containing $0.8 \mathrm{pmol}$ of limiting primer and $60 \mathrm{pmol}$ of excess primer. The PCR product was precipitated with 1.4 vol of $20 \%$ polyethylene glycol in $2.5 \mathrm{NaCl}$. The final pellet was resuspended in $10 \mu \mathrm{l}$ of distilled water and used for single stranded dideoxynucleotide sequencing ${ }^{16}$ using an internal primer (5'GCCTGGATGAGGAAGGGTG-3').

\section{Results}

The presence of a mutation of $\mathrm{C}$ (cytosine nucleotide) $\rightarrow \mathrm{T}$ (thymine nucleotide) located at amino acid position $\alpha 1-732$ in exon 40 of the COL2A1 gene destroyed a cleavage site for $T a q \mathrm{I}$ restriction endonuclease. The TaqI digest of the $631 \mathrm{bp}$ amplified fragment identified the two alleles. The normal allele is cleaved into two fragments of $475 \mathrm{bp}$ and $156 \mathrm{bp}$; the mutation destroyed the unique TaqI site and therefore the uncleaved $631 \mathrm{bp}$ fragment from the mutated allele was present along with the $475 b p+156 b p$ fragments.

The results of the screening for this mutation for diagnostic purposes is illustrated in fig 2 . It can be seen that the neonate with the Pierre-Robin sequence (III.2) is heterozygous for this mutation, showing both the uncut 631 bp product of the mutated allele and the 475 $\mathrm{bp}$ and $156 \mathrm{bp}$ products of the restriction enzyme cut normal allele. His affected paternal uncle (II.I), the original proband, and his affected son III.1 show the same pattern, whereas the unaffected subject shows the normal restriction pattern of $475 \mathrm{bp}$ and $156 \mathrm{bp}$. Restriction digest analysis results were verified by direct sequencing of an asymmetrically amplified PCR product and the neonate was shown to be a heterozygote on the sequencing gel (fig 3).

\section{Conclusions}

We have used PCR amplification and restriction digest analysis to identify the loss of a cleavage site for a $T a q \mathrm{I}$ restriction endonuclease by the mutation of $\mathrm{C}$ (cytosine nucleotide) $\rightarrow \mathrm{T}$ (thymine nucleotide) located at amino acid position $\alpha 1-732$ in exon 40 of the COL2A1 gene. We had previously reported this mutation in a three generation pedigree affected with Stickler syndrome. The mutation had been previously detected by isolation and sequencing of a cosmid clone containing the mutated allele, but no restriction site alteration was reported. Allele specific oligonucleotide 
(ASO) hybridisation was used to screen the other members of the family. ${ }^{4}$ Mutation detection by cosmid cloning, ASO hybridisation, or direct sequencing of PCR products involves radioactivity and is laborious, time consuming, and significantly more expensive. This PCR based restriction digest assay is a simple, rapid, and non-radioactive method which we have used to identify the mutation in the COL2A1 gene in one pedigree with Stickler syndrome.

Using this assay, we established the diagnosis of Stickler syndrome in a neonate from the same pedigree, presenting with the PierreRobin sequence, who had no significant ocular findings. This was the first documented report of the Pierre-Robin sequence in this particular family. The father (II.2) of the neonate was not available for our initial study or this present one. Family history indicated that he was affected. The Pierre-Robin anomalad is a fairly common birth defect and occurs in a group of over 30 syndromes besides Stickler syndrome, the majority of which have no phenotypic overlap. ${ }^{17}{ }^{18}$ This assay showed that III. 2 was indeed affected with Stickler syndrome and the Pierre-Robin anomaly was an associated abnormality. Owing to the tremendous heterogeneity of the Pierre-Robin sequence, treatment must be varied according to both the primary aetiology and the specific mechanism of the airway obstruction, and its eventual prognosis is variable depending on the association with multiple anomaly syndromes. Many patients with Stickler syndrome have truly hypoplastic mandibles so mandibular catch up growth will not occur, and the only effective form of airway management is a tracheotomy until mandibular repositioning is possible. An abnormally acute basicranium, which is responsible for decreased diameter of the upper airway, has been reported in some Stickler patients. This is another factor to consider before empirically deciding that an infant with micrognathia and apnoea has glossoptosis, thereby affecting

$\begin{array}{cc}\begin{array}{c}\text { Affected } \\ \text { heterozygote }\end{array} & \begin{array}{c}\text { Normal } \\ \text { homozygote }\end{array}\end{array}$
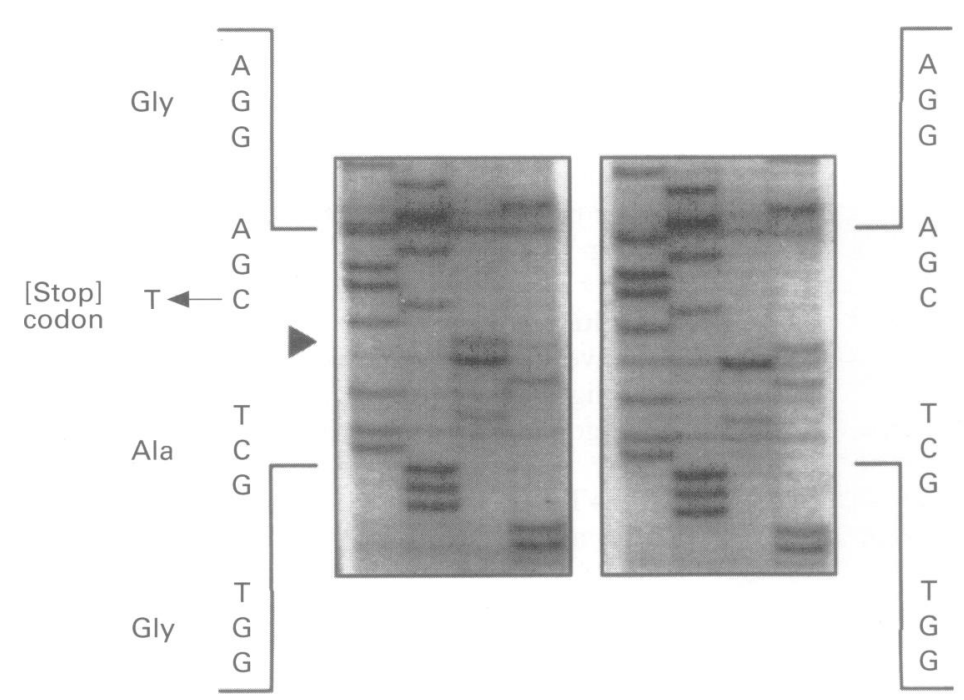

Gly

Arg

Figure 3 Direct sequencing of PCR product of the affected heterozygous neonate (III.2) and the unaffected homozygote. An arrowhead marks the single base substitution of a $T$ for a $C$ in one allele. treatment options. ${ }^{19}$ A preoperative syndromic diagnosis is essential in a cleft repair since different syndromes with clefting can result in intraoperative and postoperative problems, which will be dependent on the syndromic feature that causes the airway obstruction. Caution should be exercised in children with Stickler syndrome since sudden closure of the palate and associated swelling may cause an acute airway problem in the immediate postoperative period. For these patients it is wise to consider leaving the endotracheal tube in place for longer than normal after the operation. ${ }^{20}$ Although there were no significant ocular findings, patient III.3 will need ophthalmological examinations in early infancy and at regular intervals thereafter to rule out any progressive ocular problems. Deteriorating visual acuity is usually a result of a complication rather than progressive myopia and warrants a careful examination for cataracts or retinal changes. Audiological examination is warranted to exclude deafness, which could be sensorineural or because of middle ear disorders associated with the cleft palate deformity. Hence, detection of the mutation in the COL2Al gene in one allele of the neonate (III.3) has immediate as well as long term implications for his treatment and future prognosis.

These results emphasise the potential diagnostic value of assaying for many as yet undetected DNA mutations in families affected with Stickler syndrome. The detection of DNA mutations for the clinical diagnosis of Stickler syndrome is limited by the fact that so far each affected family has a unique mutation. Hence, each family will require a customised assay for detection. Design of rapid PCR based assays of these mutations will help avoid pitfalls in genetic counselling owing to the variability of the phenotype of Stickler syndrome both between families as well as within each family. In cases where the mutation does not alter a restriction site, an artificial restriction site can be introduced using a modified primer during PCR amplification, which creates a restriction fragment length polymorphism indicative of the mutation studied. ${ }^{2122}$

The heterogeneity of heritable connective tissue diseases such as Stickler syndrome have created problems with syndromic boundaries, nomenclature, and classification. Locus heterogeneity has been indicated by linkage analysis results, with about two-thirds of the families showing linkage to the COL2A1 gene. Although the compiled data are apparently consistent with genetic heterogeneity, raising the question of a second locus, so far they do not allow a definitive conclusion and additional families will be required to obtain significant results. In addition to the genetic heterogeneity, phenotypic variability is also a hallmark of Stickler syndrome. Unfortunately, no correlation between the clinical features and the presence or absence of recombination with the COL2A1 gene emerges from linkage studies. Hence, a precise clinical distinction of Stickler and related syndromes is not feasible based solely on linkage data. ${ }^{12}$ However, a clinical classification based on the vitreoretinal pheno- 
type has shown that those patients with a congenital retrolental vitreous anomaly with no discernible collagen structure show complete linkage to the COL2A1 gene. Conversely, in patients without the retrolental vitreous anomaly and limited random collagen fibrils, but also showing congenitally abnormal vitreous architecture, linkage to the COL2A1 gene was excluded. If further studies show that the congenital vitreous anomaly is consistently associated with mutations in the COL2A1 gene, and that these create premature termination codons, it will have useful clinical applications, particularly for carrier detection.

This work was supported in part by a grant from the National Institutes of Health IR55EY10560-01A2 (NNA) and the Research to Prevent Blindness (WST).

1 Stickler GB, Belau PG, Farrell FJ, et al. Hereditary progressive arthro-ophthalmopathy. Mayo Clin Proc 1965;40:43355.

Opitz JM, France T, Hermann J, Springer
syndrome. $N$ Engl f Med 1972;286:546-7.

syndrome. N Engl f Med 1972;286:546-7.

Blair NP, Albert DM, Lieberfarb RM, Hirose T. Hereditary progressive arthro-ophthalmopathy of Stickler. $A m \mathcal{F} O p h-$ thalmol $1993 ; 88: 876-88$.

4 Ahmad NN, Ala-Kokko L, Knowlton RG, et al. Stop codon in the procollagen gene (COL2A1) in a family with the Stickler syndrome (arthro-ophthalmopathy). Proc Natl Acad Sci USA 1991;88:6624-7.

5 Brown DM, Nichols BE, Weingist TA, Sheffield VC, Kimura AE, Stone EM. Procollagen II gene mutation in Stickler syndrome. Arch Ophthalmol 1992;110:1589-93.

6 Ahmad NN, McDonald-McGinn DM, Zackai EH, et al. A second mutation in the type II procollagen gene (COL2A1) causing Stickler syndrome (arthroophthalmopathy) is also a premature termination codon. Am f Hum Genet 1993;52:39-45.

7 Ritvaniemi P, Ignatius HJ, Kivirrikko KI, Prockop DJ, AlaKokko L. A fourth example suggests premature termination codons in the COL2A1 gene are a common cause of the Stickler syndrome. Analysis of the COL2A1 gene by denaturing gradient gel electrophoresis. Genomics 1993; 17:218-21.

8 Brown DM, Vandenburgh $\mathrm{K}$, Kimura AE, Weingeist A, Sheffield VA, Stone EM. Novel frameshift mutations in the procollagen II (COL2A1) gene associated with Stickler syndrome (hereditary arthro-ophthalmopathy). Hum Mol Genet 1995;4:41-2.

9 Ahmad NN, Dimascio J, Knowlton RG, Tasman WS. Stickler syndrome: a mutation in the non-helical 3' end of type II procollagen gene. Arch Ophthalmol 1995;113:1454-7.

10 Knowlton RG, Weaver EJ, Struyk AK, et al. Genetic linkage analysis of hereditary arthro-ophthalmopathy (Stickler syndrome) and the type II procollagen gene. $\mathrm{Am} \mathrm{f} \mathrm{Hum}$ Genet 1989;45:681-8.

11 Vintiner GM, Temple K, Middleton-Price HR, Baraitser M, Malcolm S. Genetic and clinical heterogeneity of Stickler syndrome. Am $\Im$ Med Genet 1991;41:44-8.

12 Bonaventure J, Philippe C, Pleiss G, et al. Linkage study in a large pedigree with Stickler syndrome: exclusion of COL2A1 as the mutant gene. Hum Genet 1992;90:164-8.

13 Brunner HG, van Beersum SEC, Warman ML, Olsen BR, Roper HH, Mariman EC. A Stickler syndrome gene is linked to chromosome 6 near the COL11A2 gene. Hum Mol Genet 1994;3:1561-4.

14 Vikkula M, Mariman EC, Lui VC, et al. Autosomal dominant and recessive osteochondrodysplasias associated with the COL11A2 locus. Cell 1995;80:431-7.

15 Brown DM, Graemiger RA, Hergersberg M, et al. Genetic linkage of Wagner disease and erosive vitreoretinopathy to chromosome 5q13-14. Arch Ophthalmol 1995;113:671-5.

16 Sanger F, Nicklen S, Coulson AR. DNA sequencing with chain-terminating inhibitors. Proc Natl Acad Sci USA 1977;74:5463-7.

17 Wilson GN. Human congenital anomalies: application of new genetic tools and concepts. Semin Perinatol 1992; 16:385-400.

18 Gorlin RJ, Cohen MM Jr, Levin LS. Syndromes of the head and neck. 3rd ed. New York: Oxford University Press, 1990:701-5.

19 Shprintzen RJ. Craniofacial surgery: Pierre Robin, micrognathia, and obstruction: the dependency of treatment on accurate diagnosis. Int Anesthesiol Clin 1988;26:64-71.

20 Munro IR. Craniofacial surgery: airway problems and management. Int Anesthesiol Clin 1988;26:72-8.

21 Haliassos A, Chomel JC, Kruh J, Kaplan JC, Kitzis A. Detection of minority point mutation by modified PCR technique: a new approach for a sensitive diagnosis of tumor progression markers. Nucleic Acids Res 1989; 17:8093-9.

22 Williams CJ, Harrison DA, Hopkinson I, et al. Detection of sequence variants in the gene for human type II procollagen (COL2A 1 ) by direct sequencing of polymerase chain reaction-amplified genomic DNA. Hum Mutat 1992; 1:403-16.

23 Snead MP, Stewart JP, Barton DE, et al. Stickler syndrome: correlation between vitreoretinal phenotypes and linkage to COL2A1. Eye 1994;8:609-14. 